\title{
Indigo Degradation with Laccases from Polyporus sp. and Sclerotium rolfsii
}

\author{
Rui Campos and Artur Cavaco-Paulo \\ Department of Textile Engineering, Universidade do Minho, P-4800 Guimarães, Portugal \\ Karl-Heinz Robra, Monika Schneider and Georg Gübitz \\ Department of Environmental Biotechnology, Graz. University of Technology, A-8010 Graz, Austria
}

\begin{abstract}
We have investigated the potential of fungal laccases from Polyporus sp. and Sclerotium rolfsii to degrade insoluble indigo. Evidence shows that both laccases are able to oxidize insoluble indigo to give isatin (indole-2,3-dione), which further degrades to anthranilic acid (2-aminobenzoic acid). Adsorption studies show that the laccase from Polyporus sp. has a higher affinity for indigo than the laccase of Sclerotium rolfsii. The particle size of indigo agglomerates is influenced by the origin of the laccase preparation and the incubation time. The potential of laccases to modify indigo stained fabrics is assessed. Treatment of indigo dyed fabrics with laccase prevents indigo backstaining, and Polyporus sp. appears to be more effective for reducing backstaining.
\end{abstract}

In denim garment processing, several steps are involved between dyeing and the final stone washing. During these processes, excessive amounts of indigo are removed from the fabrics and discharged with the waste water. Effluents discharged from textile and dyestuff industries to neighboring water bodies and waste-water treatment systems currently cause significant problems for environmental regulatory agencies. Interest in the pollution potential of textile dyes has primarily been prompted by concern over their possible toxicity and carcinogenicity [16]. Indigo cannot be easily degraded or removed with physical and chemical processes [17]. Untreated effluents from indigo dyeing mills may be highly colored and thus particularly objectionable if discharged into open waters. As a textile dye, indigo is environmentally important because of its widespread use and its potential for forming toxic aromatic amines [17].

In general, the ability of micro-organisms to decolor dyes has received much attention. Microbial decoloring and degradation of dyes is seen as a cost-effective method for removing these pollutants from the environment, and may open up possibilities for reusing dyeing effluents and reducing water consumption [17].

Laccases (benzenediol: oxygen oxidoreductase, EC 1.10.3.2) have a very broad substrate specificity with respect to the electron donor. They catalyze the removal of a hydrogen atom from the hydroxyl group of orthoand para-substituted mono- and polyphenolic substrates and from aromatic amines by one electron abstraction to form free radicals capable of undergoing further depolymerization, repolymerization, demythylation, or quinone formation [12]. Although laccases exclusively accept oxygen as their oxidizing substrate, they have rather low specificity against their reducing substrates [11, 18, 19].

Proteins or other substances pre-adsorbed on the fabrics are the major reason for indigo backstaining (redeposition of dye) on denim fabrics $[1,6,7]$. Laccases have been reported to bleach indigo fabrics $[10,13]$, and laccase-based systems are able to degrade indigo both in solution and on denim, leading to various bleaching effects on the fabric $[10,14,15]$. Another laccase application is the oxidative transformation or polymerization of dye precursors to improve dyeing efficiency [10].

The biodegradability of indigo and its industrial effluents by fungi has been studied with Phellinus gilvus, Phanerochaete chrysporium, Pycnoporus sanguineus, and Pleurotus sajor-caju. Tests of immediate biodegradability have proved that indigo can be classified as easily biodegradable by fungi, and toxicity is greatly reduced [3].

In this work, we report on the degradation of indigo, both in effluents and on fabrics, with two laccase preparations from Polyporus sp. and Sclerotium rolfsii. We discuss the general principles of enzyme-catalyzed reactions on indigo and the problems that may arise with application and interpretation.

\section{Experimental}

Enzyme assay: Laccase (benzenediol: oxygen oxireductase, EC 1.10.3.2) activity was determined using 2,6dimethoxyphenol (DMP) as a substrate. The reaction mixture contained $50 \mathrm{mmol}$ sodium malonate ( $\mathrm{pH} 4.5$ ), $1 \mathrm{mmol}$ DMP, $1 \mathrm{mmol} \mathrm{MnSO}_{4}$, and a $700 \mu \mathrm{l}$ sample in a total of 1 
$\mathrm{ml}$. Formation of an orange/brownish dimer was followed spectrophotometrically at $468 \mathrm{~nm}$ (laccase activity).

Adsorption experiments: $1 \mathrm{mg}$ insoluble indigo (BASF) was incubated in solutions $(4 \mathrm{ml})$ containing $0.0-0.3 \mathrm{mg}$ $\mathrm{ml}^{-1}$ (protein) laccase preparations from Polyporus sp. and Sclerotium rolfsii under mechanical agitation in a water bath shaker at $200 \mathrm{rpm}$ and $30^{\circ} \mathrm{C}$ for 20 hours. Subsequently, the mixtures were vacuum filtered and the adsorption of laccase protein onto the indigo was determined by measuring protein in solution by the Bradford method [5]. Indigo particle size changes during laccase treatment were followed with a Malvern Mastersizer apparatus.

Decoloring experiments: Typically, $1 \mathrm{mg}$ insoluble indigo, $500 \mu \mathrm{l}$ enzyme preparation (diluted to give 0.1 nkat $\mathrm{ml}^{-1}$ final laccase activity), and $3.5 \mathrm{ml}$ buffer $(0.1$ $M$ sodium acetate, $\mathrm{pH} 5.0$ ) in glass tubes were incubated in a rotary shaker at $30^{\circ} \mathrm{C}$ for various time intervals. The indigo degradation products were analyzed using an HPLC apparatus (MT2 version 422S) from Kontron, equipped with two high pressure pumps $422 \mathrm{~S}$, a mixer M800, an autosampler 455 , a pre-column $(7 \times 4 \mathrm{~mm})$, and a $(25$ $\times 4 \mathrm{~mm}$ ) Hypersyl ODS $5 \mu \mathrm{m}$ column, uv detector 430 (two channels). The mobile phase was a degassed mixture of $60 \%$ methanol in $40 \%$ water for quantifying the insoluble indigo degradation products. The wavelengths used for indigo degradation products were 320 and $400 \mathrm{~nm}$. To detect insoluble indigo, the dye was dissolved with $\mathrm{K}_{2} \mathrm{Cr}_{2} \mathrm{O}_{7}(0.061 \mathrm{mmol})$ at the boil and quantified spectrophotometrically at $441 \mathrm{~nm}$ using calibration curves.

Dye removal from fabric: Indigo stained fabrics were washed with ice-chilled buffer ( $\mathrm{pH} 4.85$, acid acetic/ $\mathrm{NaOH}$ ). After 20 minutes, samples were taken and 46.4 $\mathrm{mg}$ indigo/g fabric added. Washing continued for a further 20 minutes. To remove excess indigo, fabrics were washed for 20 minutes in cold water in a commercial washing machine, rinsed, and line dried. Staining levels $(K / S)$ were measured at $650 \mathrm{~nm}$ (ACS II spectrometer).

Indigo washing experiments involved fabrics stained with $100 \mu \mathrm{g}$ indigo. Enzyme preparations, diluted to give 0.1 nkat $\mathrm{ml}^{-1}$ final laccase activity, were added and incubated in Erlenmeyer flasks on a rotary shaker for 24 hours. After centrifuging, indigo degradation products were quantified with HPLC, and insoluble indigo was quantified as described above. Indigo stained fabrics were rinsed and dried and the staining levels $(K / S)$ were measured at $650 \mathrm{~nm}$ (ACS II spectrometer).

\section{Results and Discussion}

Indigo-laccase adsorption: Interactions of indigo with laccases (Figure 1) seem to be comparable to common physicochemical phenomena, which can be described by the Langmuir model [4]. The same model was used previously for adsorption of indigo onto cellulases [6] as well as onto cotton [4]. We calculated estimated adsorption constants $\left(k_{a}\right)$ and estimated saturation levels of indigo on Polyporus sp. and Sclerotium rolfsii laccases based on the Langmuir model by nonlinear regression analysis (Table I). Isotherms are shown in Figure 1.

TABLE L. Parameters of protein adsorption on insoluble indigo.

\begin{tabular}{lcc}
\hline \multicolumn{1}{c}{ Laccase } & $K_{a}, \mathrm{ml} / \mathrm{mg}$ & $\begin{array}{c}\text { Saturation level, } \\
\mathrm{mg} \mathrm{mg}^{-1} \text { indigo/protein }\end{array}$ \\
\hline Polyporus sp. & $0.0467 \pm 0.0142$ & $0.1082 \pm 0.0096$ \\
Sclerotium rolfsii & $0.0357 \pm 0.0108$ & $0.0673 \pm 0.0046$ \\
\hline
\end{tabular}

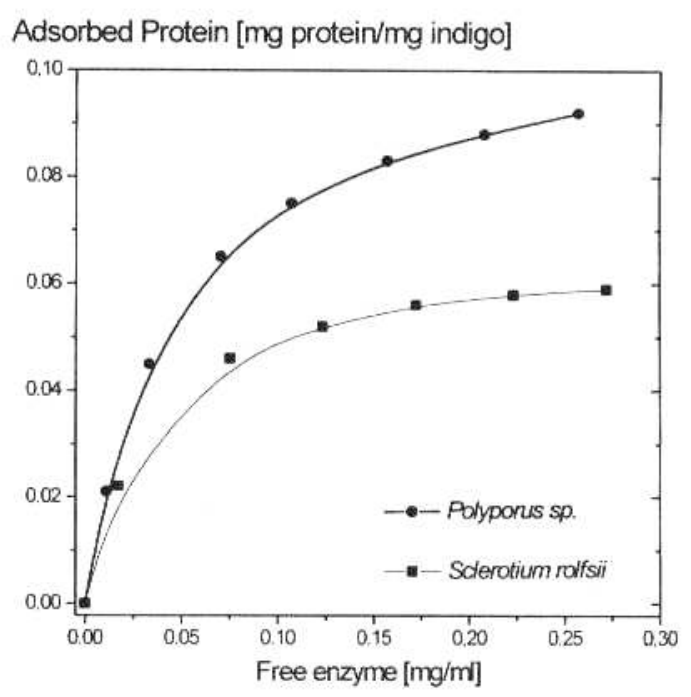

FigurE I. Langmuir isotherms for adsorption of laccases onto insoluble indigo.

The isotherms for both laccases show a typical saturation profile. The calculated parameters and the respective Langmuir isotherms indicate that indigo has a higher affinity for the laccases from Polyporus sp. than for $S$. rolfsii. This is indicated by a higher $k_{a}$ value and a higher saturation level, which can be explained by an increased number of adsorption sites for indigo on the Polyporus $s p$. laccase molecules. Differences in amino acid residues and protein architecture seem to be the main reasons for the different binding behaviors.

Indigo particle size: For better understanding of indigo interactions with laccases, interactions of proteins (laccases) and indigo were simulated by incubating laccases from Polyporus sp. and Sclerotium rolfsii with indigo and measuring the particle size of the resulting dispersion. Figures 2 and 3 show the diameter distribution of particles formed between indigo and Polyporus sp. and $S$. rolfsii laccases after various incubation times. Distributions had one maximum. Compared to the indigo 


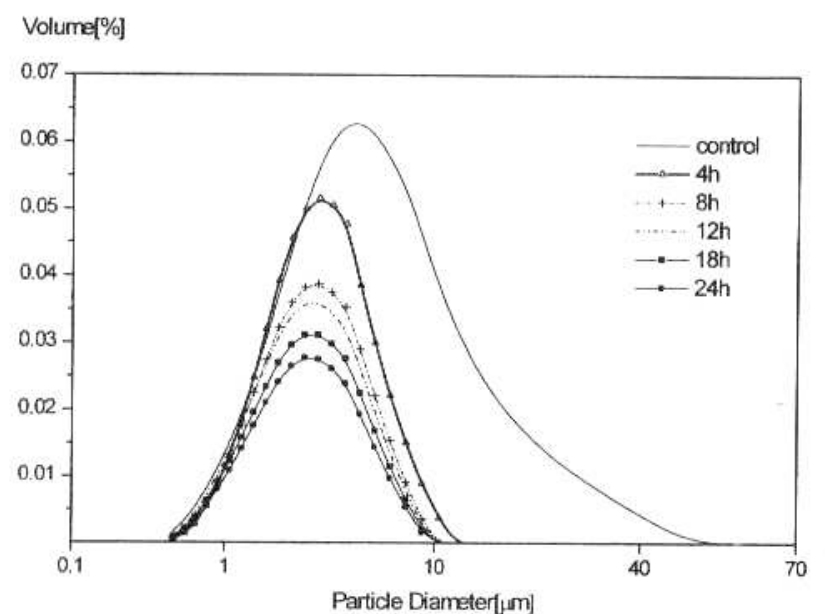

FIGURE 2. Particle diameter distribution of indigo incubated with the Polyporus sp. laccase.

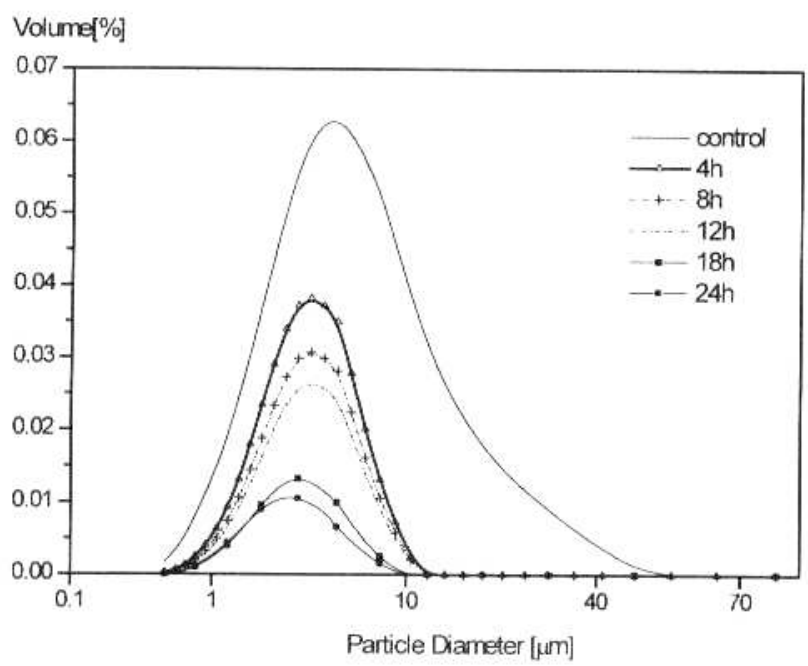

Figure 3. Particle diameter distribution of indigo incubated with the $S$. rolfsii laccase.

particle size distribution of the control, for both laccases the indigo-laccase agglomerates seemed to have shifted to smaller diameters. Indigo agglomerates were fractionated into smaller particles when they were incubated with Polyporus sp. laccase (Figure 2), which seems to have a higher affinity for indigo than the $S$. rolfsii laccase. For both enzymes, the longer incubation times seem to decrease the size of the indigo agglomerates that form. The concentration $(\% \mathrm{v} / \mathrm{v})$ of the particles at the maximum distribution seems to decrease with time. This could mean that in the dispersion, indigo degrades into more soluble products. Thus, binding indigo molecules to Polyporus sp. and $S$. rolfsii laccases may somehow separate agglomerates. Therefore, in the stonewashing process, binding indigo to laccases can decrease backstaining.
Indigo degradation products: The activity of laccases can either be measured by determining the rate of product formation or substrate utilization during the enzymecatalyzed reaction. The time-course of product formation and substrate utilization of the Polyporus sp. and Sclerotium rolfsii laccases for degrading indigo is shown in Figures 4 and 6 . Indigo is degraded by laccases into isatin, which is further decomposed to give anthranilic acid as a final reaction product. The time-course is initially almost linear, but the rate of product formation starts to decline at longer times. The behavior of such a system can be complex if an insoluble substrate (indigo) is used, and adsorption and transport limitations have to be considered with enzyme kinetics.

Interestingly, indigo degradation is more efficient when Polyporus sp. is added. Indigo is converted faster into isatin, and after 18 hours all isatin has decomposed, yielding anthranilic acid.

Removal of dye from fabrics: Indigo backstaining can be reduced by decoloring the dye solubilized from denim fabrics with laccases. Figure 5 shows that the fabrics treated with laccases are more extensively bleached than the control fabrics. Comparing the performance of the two laccases, the Polyporus sp. is more effective at reducing backstaining on the fabrics. A possible reason for this effect is the higher affinity of the Polyporus sp. laccase to indigo. Fabrics treated only with buffer also release indigo into the solution. The presence of the laccase in solution will reduce backstaining, even when less buffer is used, because indigo will be degraded into products that do not adsorb onto the cotton fabrics.

\section{Conclusions}

The results of our work show that laccases from both Polyporus sp. and Sclerotium rolfsii can efficiently degrade insoluble indigo, which has a higher affinity for Polyporus sp. than Sclerotium rolfsii. Results obtained with particle size measurements of indigo agglomerates indicate that the distributions have one maximum. Compared to the distribution of indigo particle sizes in a control, the indigo-laccase agglomerates seem to have shifted to smaller diameters. Thus, binding indigo molecules to Polyporus sp. and $S$. rolfsii laccases may somehow separate agglomerates. Indigo agglomerates fractionate into smaller particles when incubated with the Polyporus sp. laccase than with the $S$. rolfsii laccase.

The indigo degradation product is isatin (indole-2,3dione), which further decomposes to anthranilic acid (2-aminobenzoic acid). Oxidation of substrates by lac- 
FIGURE 4. Indigo degradation products formed by enzyme preparations from Polyporus $s p$. and S. rolfsii.

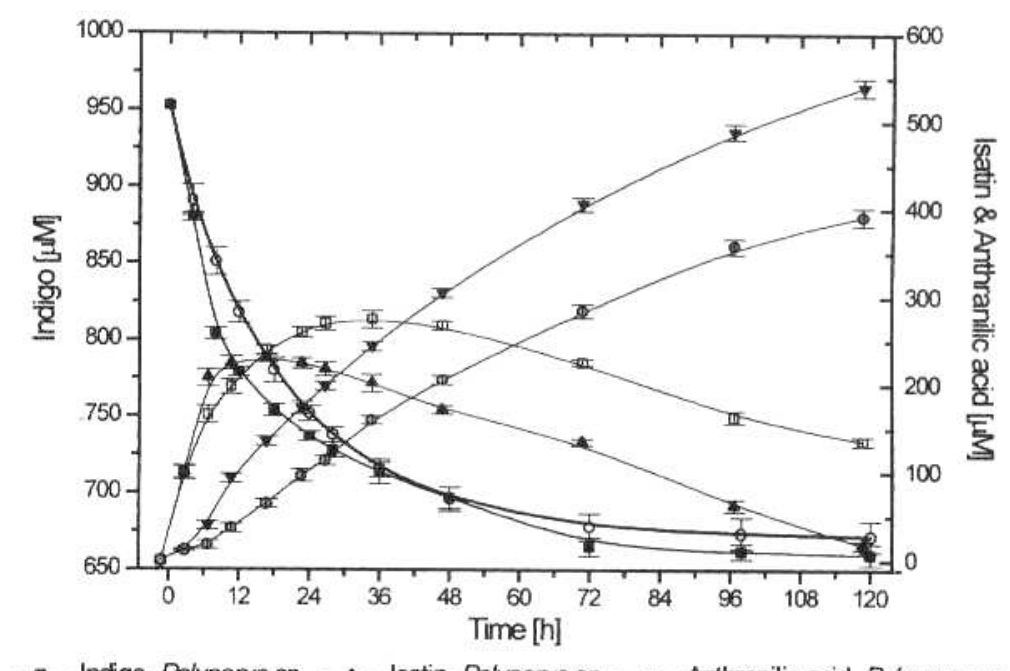

- - Indigo- Polyporus sp. _- Isatin- Polyponis sp. - - Anthranilic acid- Polyporus sp. $\rightarrow-$ Indigo-S.rolfsii $\quad-\square-$ Isatin-S. rolfsij $\rightarrow$ Anthranilic acio- S.rolfsii

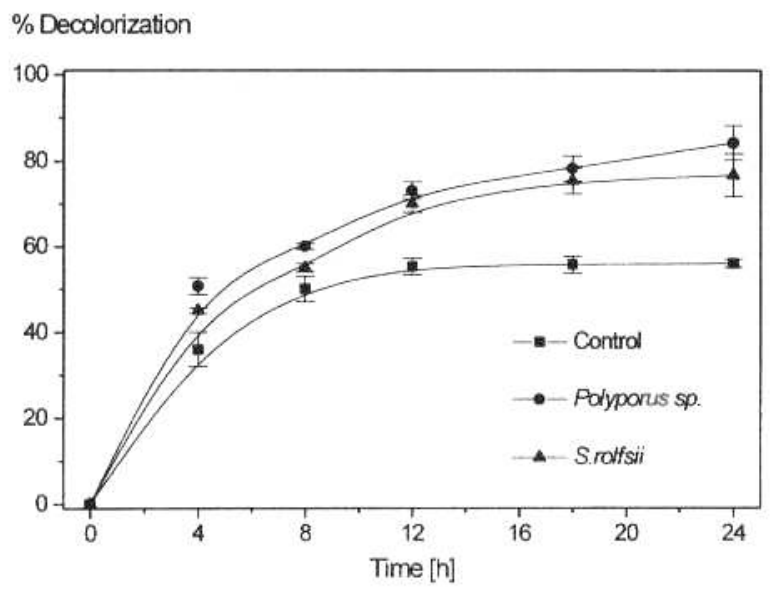

FIGURE 5. Enzymatic decolorizing of indigo stained fabrics by enzyme preparations from Polyporus sp. and $S$. rolfsii. case is believed to involve the reduction of molecular oxygen. The kinetics of indigo degradation with laccases shows that Polyporus sp. laccases are more effective due the faster conversion of indigo into isatin, which further decomposes to anthranilic acid as a final reaction product. Similarly, Polyporus sp. laccases are more effective in reducing indigo backstaining.

Laccase-catalyzed bleaching of indigo may be very useful in finishing dyed cotton fabrics. Replacing conventional chemical oxidants [13] with a laccase-based system allows indigo bleaching in denim and achieves various bleached levels on the fabric $[14,15]$. Furthermore, decoloring indigo in dyeing effluents will allow recycling of the water and/or less environmental pollution.
FIGURE 6. Indigo degradation products formed from indigo stained fabrics treated with enzyme preparations from Polyporus sp. and $S$, rolfsii

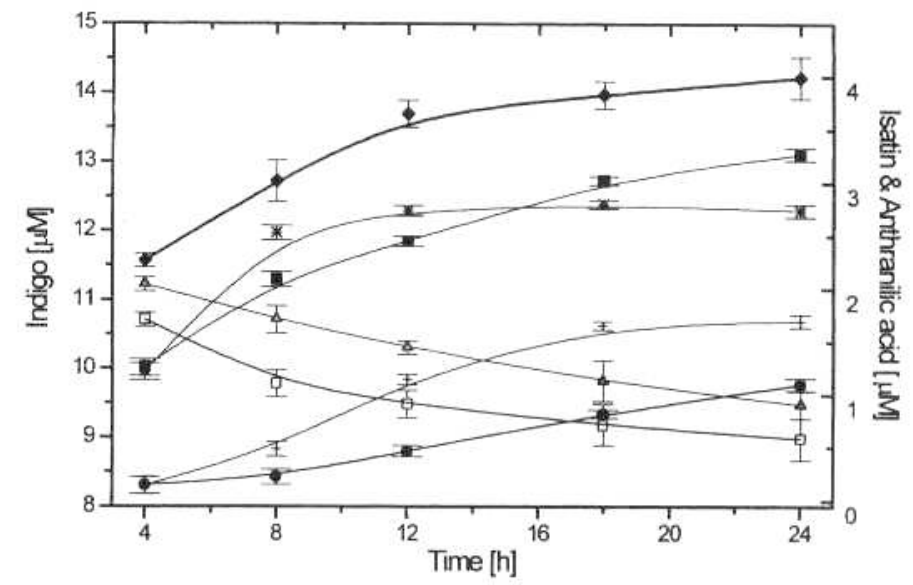

- - Indigo- Polyporus so.

- - Indigo- Without enzyme - - - Isatin-Polyporus sp. -+- Anthranilic acid- polyponus sp - A- Indigo-S. rolfsii $\quad-$ - Isatin-S. rolfsii $\rightarrow$ - Anthranilic acid- S. rolfsii 


\section{Literature Cited}

1. Andreaus, J., Campos, R., Gübitz, G., and Cavaco-Paulo, A., Influence of Cellulases on Indigo Backstaining. Textile Res. J. 70, 628-632 (2000).

2. Balan, D. S. L., and Monteiro, R. T. R., Descolorização de Indigotina Azul por Basidiomicetos Ligninolítiticos, in "Workshop sobre Biodegradação, Campinas SP, Anais," 1996, p. 252.

3. Cavaco-Paulo, A., Almeida, L., and Bishop, D., Hydrolysis of Cotton Cellulose by Engineered Cellulases from Trichoderma reesei, Textile Res. J. 68(4), 273-280 (1998).

4. Bradford, M., A Rapid and Sensitive Method for the Quantitation of Microgram Quantities of Protein Utilizing the Principle of Protein-Dye Binding, Anal. Biochem 72, 248-254 (1976).

5. Campos, R., Cavaco-Paulo, A., Andreaus, J., and Gübitz, G., Indigo-Cellulase Interactions, Textile Res. I. 70, $532-$ 536 (2000).

6. Cavaco-Paulo, A., Morgado, José A., Almeida, L., and Kilburn, Douglas, Indigo Backstaining During Cellulase Washing, Textile Res. J. 68(6), 398-401 (1998).

7. Doukyu, N., Tomonori, A., and Aono, R., Effects of Organic Solvents on Indigo Formation by Pseudomonas $s p$. Strain ST-200 Grown with High Levels of Indole, Biosci. Biotechnol. Biochem. 62(6), 1075-1080 (1998).

8. Eaton, R. W., and Chapman, P. J., Formation of Indigo Compounds from Indolecarboxylic Acids by Aromatic Acid-Degrading Bacteria: Chromogenic Reactions for
Cloning Genes Encoding Dioxygenases that Act on Aromatic Acids, J. Bacteriol. 177(23), 6983-6988 (1995).

9. Flickinger, M. C., and Drew, S. W., Eds., "Encyclopedia of Bioprocess Technology: Fermentation, Biocatalysis and Bioseparation," John Wiley, NY, 1999, p. 1545-1554.

10. Gianfreda, L., Xu, F., and Bollag, J. M., Laccases: A Useful Group of Oxidoreductive Enzymes, Bioremediation J. 3(1), 1-25 (1999).

11. Goncalves, M. L., and Steiner, W., Use of Laccase for Bleaching of Pulps and Treatment of Effluents, ACS Symp. Ser. 655, 197-206 (1996).

12. International pat. 9218687 , October 29, 1992, G. Pedersen and $M$. Schmidt to Novo Nordisk A/S.

13. International pat. 9612845 Al, May 2, 1996, A. H. Pedersen and J. V. Kierulff to Novo Nordisk A/S.

14. International pat. 9612846 A1, May 2, 1996, A. H. Pedersen and J. V. Kierulff to Novo Nordisk A/S

15. Pierce, J., Colour in Textile Effluents-The Origins of the Problem, J. Soc. Dyers Colour. 110, 131-134 (1994).

16. Nigam, P., and Mullan, G. M., Decolourization of Effluent from the Textile Industry by a Microbial Consortium, Biotechnol. Lett. 18(1), 117-120 (1996).

17. Thurston, C. F., The Structure and Function of Fungal Laccases, Microbiology 140, 19-26 (1994).

18. Yaropolov, A. I., Skorobogat'ko, O. V., Vartanov, S. S., and Varfolomeyev, S. D., Laccase: Properties, Catalytic Mechanism, and Applicability, Appl. Biochem. Biotechnol. 49, 257-280 (1994).

Munuscript received April 15, 2000; accepted fune 23, 2000. 